\title{
CAM-related changes in chloroplastic metabolism of Mesembryanthemum crystallinum $\mathrm{L}$.
}

\author{
Ewa Niewiadomska $\cdot$ Wolfgang Bilger $\cdot$ \\ Magdalena Gruca $\cdot$ Maria Mulisch • \\ Zbigniew Miszalski $\cdot$ Karin Krupinska
}

Received: 20 September 2010/Accepted: 12 October 2010/Published online: 3 November 2010

(C) The Author(s) 2010. This article is published with open access at Springerlink.com

\begin{abstract}
Crassulacean acid metabolism (CAM) is an intriguing metabolic strategy to maintain photosynthesis under conditions of closed stomata. A shift from $\mathrm{C}_{3}$ photosynthesis to CAM in Mesembryanthemum crystallinum plants was induced by high salinity $(0.4 \mathrm{M} \mathrm{NaCl})$. In CAM-performing plants, the quantum efficiencies of photosystem II and I were observed to undergo distinct diurnal fluctuations that were characterized by a strong decline at the onset of the day, midday recovery, and an evening drop. The temporal recovery of both photosystems' efficiency at midday was associated with a more rapid induction of the electron transport rate at PSII. This recovery of the photosynthetic apparatus at midday was observed to be accompanied by extreme swelling of thylakoids. Despite these fluctuations, a persistent effect of CAM was the acceptor side limitation of PSI during the
\end{abstract}

E. Niewiadomska ( $\square)$

Institute of Biology, The Jan Kochanowski University

of Humanities and Science, Świętokrzyska 15,

25-406 Kielce, Poland

e-mail: e.niewiadomska@ifr-pan.krakow.pl

E. Niewiadomska $\cdot$ M. Gruca $\cdot$ Z. Miszalski

Institute of Plant Physiology, Polish Academy of Sciences,

Niezapominajek 21, 30-239 Kraków, Poland

W. Bilger · K. Krupinska

Institute of Botany, Christian-Albrechts-University of Kiel,

Olshausenstr. 40, 24098 Kiel, Germany

M. Mulisch · K. Krupinska

Central Microscopy, Biology Center,

Christian-Albrechts-University of Kiel, Kiel, Germany

Z. Miszalski

Institute of Biology, Pedagogical University,

Podbrzezie 3, 31-054 Kraków, Poland day, which was accompanied by a strongly decreased level of Rubisco protein. Diurnal changes in the efficiency of photosystems were parallel to corresponding changes in the levels of mRNAs for proteins of PSII and PSI reaction centers and for $r b c L$, reaching a maximum in CAM plants at midday. This might reflect a high demand for new protein synthesis at this time of the day. Hybridization of run-on transcripts with specific probes for plastid genes of $M$. crystallinum revealed that the changes in plastidic mRNA levels were regulated at the level of transcription.

Keywords Chloroplast ultrastructure - Dual PAM . Photosynthesis related genes - Photosystem I and II efficiency $\cdot$ Plastid run-on transcription $\cdot$ Rubisco

$\begin{array}{ll}\text { Abbreviations } \\ \text { BCIP } & \text { 5-Bromo-4-chloro-3-indolyl phosphate } \\ \text { CAM } & \text { Crassulacean acid metabolism } \\ \text { CCM } & \text { Carbon concentrating mechanism } \\ \text { ETR } & \text { Electron transport rate } \\ \text { NADP-ME } & \text { NADP-dependent malic enzyme } \\ \text { NBT } & \text { Nitro blue tetrazolium } \\ \text { NPQ } & \text { Non-photochemical quenching of PSII } \\ & \text { fluorescence } \\ \text { PEPC } & \text { Phosphoenolpyruvate carboxylase } \\ \text { PET } & \text { Photosynthetic electron transport } \\ \text { Rubisco } & \text { Ribulose bisphosphate carboxylase/ } \\ & \text { oxygenase } \\ \text { SDS } & \text { Sodium dodecyl sulfate } \\ \text { SP } & \text { Pulse of saturating light } \\ \text { Y(I) } & \text { Quantum efficiency of PSI } \\ \text { Y(II) } & \text { Quantum efficiency of PSII } \\ \text { Y }_{\text {ND }} & \text { Donor side limitation of PSI } \\ \text { Y }_{\text {NA }} & \text { Acceptor side limitation of PSI }\end{array}$




\section{Introduction}

Crassulacean acid metabolism (CAM) is a strategy to maintain photosynthesis under conditions of closed stomata. Owing to its release from carboxylic acids formed during the night, $\mathrm{CO}_{2}$ in CAM plants can be converted into sugar by the Calvin cycle despite the gas exchange is prevented (Cushman and Bohnert 1999). Photosynthesis of the CAM type is, however, not uniform over the day, but undergoes diurnal changes, which can be assigned to four distinct phases with respect to the predominant enzyme active in carboxylation (Osmond 1978; Winter and Smith 1996; Borland and Taybi 2004; Winter and Holtum 2007). While at night fixation of $\mathrm{CO}_{2}$ by PEPC leads to accumulation of carboxylic acids (phase I), at the onset of the day (phase II) stomata temporarily open and a transition from carboxylation by PEPC to carboxylation mediated by Rubisco occurs. Decarboxylation of carboxylic acids in concert with the fixation of $\mathrm{CO}_{2}$ by Rubisco during most time of the day (phase III) is followed by a transition to $\mathrm{C}_{3}$ photosynthesis towards the end of the day when resources of accumulated $\mathrm{CO}_{2}$ are depleted (phase IV). Mesophyll cells of CAM plants are subjected to considerable fluctuations of the internal $\mathrm{CO}_{2}$ level. During phases I and II, they have a low level of $\mathrm{CO}_{2}$ and high acidification, in phase III $\mathrm{CO}_{2}$ concentration is increased and accompanied by an increased level of oxygen, and then the level of $\mathrm{CO}_{2}$ is decreased again in phase IV.

$\mathrm{C}_{3}$ metabolism requires ATP for the Calvin cycle for starch and sucrose synthesis, photorespiration and nitrate reduction (Noctor and Foyer 1998). Assuming that the activity of the Q cycle is constitutive, linear electron flow should produce as much as 3 ATP and 2 NADPH per molecule of fixed $\mathrm{CO}_{2}$. In comparison to $\mathrm{C}_{3}$ plants, energy requirement for $\mathrm{CO}_{2}$ fixation is higher in CAM plants (Nobel 1991; Winter and Smith 1996; Lüttge 2004). The precise stoichiometry of ATP and NADPH, however, depends on the type of carbohydrates produced in the light (chloroplastic starch or extrachloroplastic hexose and sucrose), the type of organic acids stored in the dark (malate, citrate and isocitrate), the way of acid decarboxylation (mitochondrial NAD-ME, cytosolic NADP-ME or PEP carboxykinase, PEPCK), the kind of vacuolar transport (tonoplast ATPase and inorganic pyrophosphatase, PPase), as reviewed by Winter and Smith (1996) and Lüttge (2004). In the light period, ATP is required for the regeneration of pyruvate via gluconeogenesis and in the dark period for the regeneration of PEP from pyruvate, for reduction of OAA to malate and for active transport of malate to the vacuole (Nobel 1991; Winter and Smith 1996; Lüttge 2004). Levels of ATP and NADPH in CAM plants depend on the duration of phases II and IV when $\mathrm{CO}_{2}$ is provided by open stomata. To increase ATP production during phase III of CAM, a stimulation of cyclic or pseudocyclic electron flow resembling the situation in $\mathrm{C}_{4}$ bundle sheath cells has been suggested (Köster and Winter 1985; Winter and Smith 1996; Niewiadomska and Borland 2008).

Structural analyses of chloroplasts from CAM plants showed a severe swelling of the thylakoid lumen (Paramonova et al. 2004). Chloroplasts were shown to have unstacked thylakoids and thereby to resemble chloroplasts from $\mathrm{C}_{4}$ plants of NADP-ME type which have long unstacked thylakoids (Woo et al. 1970; Edwards et al. 2004) and during development lose photosystem II (Oswald et al. 2005). Although these chloroplasts constitutively perform photosynthesis of the $\mathrm{C}_{4}$-type, chloroplasts of CAM plants in response to $\mathrm{CO}_{2}$ supply undergo diurnal changes in the type of photosynthesis; so far, it is not known whether the structure of CAM plant chloroplasts is subjected to diurnal changes paralleling the changes in the type of photosynthesis.

The goal of this work was to elucidate the structural and molecular mechanisms allowing an adjustment of the photosynthetic apparatus to the CAM-associated diurnal changes in the $\mathrm{CO}_{2}$ source. For this purpose, plants of Mesembryanthemum crystallinum were treated with high salinity known to induce a shift from $\mathrm{C}_{3^{-}}$to CAM metabolism (for a review see Adams et al. 1998; Bohnert and Cushman 2000; Ślesak et al. 2002; Winter and Holtum 2007). First, the functionality of the photosynthetic apparatus of CAM-performing plants of M. crystallinum was compared with $\mathrm{C}_{3}$ plants by chlorophyll fluorescence measurements. At specific time points of the day, furthermore, ultrastructural analysis of the thylakoid membrane structure and investigations on the levels of photosynthesisassociated proteins and their mRNAs were performed. The results suggest that in CAM plants, a high turnover of the components of the photosynthetic apparatus is required for maintaining a high-photosynthetic capacity at midday. Run-on transcription analyses with chloroplasts indicated that this is achieved by preferential transcription of photosynthesis related genes.

\section{Materials and methods}

Plant material and growth conditions

Mesembryanthemum crystallinum L. plants (common ice plant; Aizoaceae) were grown from seeds in soil in a phytotron chamber at a temperature of $24^{\circ} / 18^{\circ} \mathrm{C}(12 \mathrm{~h}$ light/12 h darkness) and relative air humidity of $60-80 \%$. Irradiance was about $200 \mu \mathrm{mol}$ photons $\mathrm{m}^{-2} \mathrm{~s}^{-1}$ (PAR range 400-700 nm) during the light period. After 4 weeks of sowing when the fourth leaf pair emerged, plants were 
irrigated with $0.4 \mathrm{M} \mathrm{NaCl}$ to induce CAM (salt-treated/ CAM plants). $C_{3}$ performing control plants were instead supplied with tap water (controls, $\mathrm{C}_{3}$ plants). CAM induction during 14 days of treatment with salinity was detected by a difference in concentration of malate in the leaf sap between 8:00 and 18:00, respectively ( $\Delta$ malate). In salinity-treated plants, $\Delta$ malate value was $114.9 \mathrm{mM}$ in comparison to $-1.51 \mathrm{mM}$ in control plants. Malate was determined as described previously (Niewiadomska et al. 1999). Development of CAM was also detected by an increased amount of PEPC (Fig. 5). For molecular analyses, third pair leaves were harvested at different time points of the day starting from the end of the night period (predawn) until the end of the light period. Leaf samples were immediately frozen in liquid nitrogen and stored at $-75^{\circ} \mathrm{C}$.

Analyses of quantum efficiencies of PSII and PSI

Quantum yields of PSII and PSI were simultaneously measured with a Dual PAM 100 fluorescence system (Heinz Walz GmbH, Effeltrich, Germany) with $\mathrm{C}_{3}$ performing control plants and CAM-induced plants (treated with salinity for 14-19 days). PSII photochemistry was investigated by means of chlorophyll $a$ fluorescence on leaves adapted to darkness for $20 \mathrm{~min}$. Quantum efficiency of PSII in the light adapted state, Y(II), and electron transport rate (ETR) were determined according to Genty et al. (1989), whereby leaf absorptivity was assumed to be 0.84. Non-photochemical quenching (NPQ) of PSII fluorescence was quantified according to Kramer et al. (2004). Quantum efficiency of PSI (Y(I)) was assessed via dual wavelength P700 measurements at 830 and $875 \mathrm{~nm}$, respectively (Klughammer and Schreiber 1994). Oxidation was induced by actinic red light of an irradiance of $126 \mu \mathrm{mol} \mathrm{m} \mathrm{s}^{-1}$. In another experiment, induction kinetics of ETR was analyzed during $300 \mathrm{~s}$ irradiance with actinic light of an irradiance of $240 \mu \mathrm{mol} \mathrm{m}^{-2} \mathrm{~s}^{-1}$ using a fluorescence imaging system (Maxi PAM, Heinz Walz $\mathrm{GmbH})$. Before illumination, the plants were kept in darkness for 15-20 min. Donor side limitation of PSI $\left(\mathrm{Y}_{\mathrm{ND}}\right)$ was calculated from reduced $\mathrm{P} 700 \quad\left(\mathrm{Y}_{\mathrm{ND}}=\right.$ 1 - P700 red). Acceptor side limitation of PSI $\left(\mathrm{Y}_{\mathrm{NA}}\right)$ was determined as change in P700 signal upon application of far red light in addition to a saturating pulse $\left(P_{\mathrm{m}}\right)$ as compared to a saturating pulse alone $\left(P_{\mathrm{m}^{\prime}}\right) \quad\left(\mathrm{Y}_{\mathrm{NA}}=\right.$ $\left.\left(P_{\mathrm{m}}-P_{\mathrm{m}^{\prime}}\right) / P_{\mathrm{m}}\right)$.

\section{Ultrastructural analyses}

Ultrastructural analyses were made on third pair leaves that were collected at the end of the night (predawn) and at midday. Small segments from the middle part of the leaves were fixed at room temperature in $2.5 \%(\mathrm{v} / \mathrm{v})$ glutaraldehyde and $1 \%(\mathrm{w} / \mathrm{v})$ formaldehyde (freshly prepared from paraformaldehyde) in $0.1 \mathrm{M}$ sodium cacodylate buffer, $\mathrm{pH}$ 7.3. After washing in buffer, the samples were postfixed in buffered $1 \%(\mathrm{w} / \mathrm{v})$ osmium tetroxide, washed, dehydrated in a graded series of ethanol and embedded in LR (London Resin, Plano GmBH, Wetzlar, Germany) white resin. The resin was polymerized at $60^{\circ} \mathrm{C}$. Ultrathin sections were cut with a diamond knife in a Leica Ultracut UCT ultramicrotome (Wetzlar, Germany). The sections were stained with saturated uranyl acetate in water and lead citrate (Reynolds 1963) and observed in a Philips EM CM10 transmission electron microscope (FEI Company, Eindhoven, The Netherlands). The analysis of thylakoids width was done with the use of ImageJ software developed at the National Institute of Health (http://rsb.info.nih.gov/ij/download.html, USA).

\section{Preparation of chloroplasts}

Chloroplasts were isolated according to the procedure of Gruissem et al. (1986) with specific modifications. For chloroplast isolation from CAM plants twice the concentration of sorbitol $(0.7 \mathrm{M})$ was used in the medium. Chloroplasts isolated from $\mathrm{C}_{3}$ plants were collected by a lower centrifugation speed aimed to prevent disruption due to their high starch content. Isolated chloroplasts from both $\mathrm{C}_{3}$ and CAM plants were re-suspended in $20 \mathrm{mM}$ Hepes buffer, $\mathrm{pH}$ 7.5.

\section{Immunoblot analyses}

For preparation of crude protein extracts, leaf material was homogenized using a cooled mortar in $100 \mathrm{mM}$ phosphate buffer, $\mathrm{pH} 7.5$, containing $1 \mathrm{mM}$ DTT and protease inhibitor cocktail (ProteoBlock ${ }^{\mathrm{TM}}$, Fermentas). After centrifugation for $5 \mathrm{~min}$ at $10,000 \mathrm{~g}$, supernatants were collected for analysis of Rubisco and PEPC. Before SDS-PAGE according to Laemmli (1970), protein samples were dissolved in buffer consisting of $125 \mathrm{mM}$ Tris- $\mathrm{HCl}$, $\mathrm{pH} 6.8,2 \%(\mathrm{w} / \mathrm{v})$ SDS, $1 \%(\mathrm{v} / \mathrm{v}) \beta$-ME, $5 \mathrm{M}$ urea and $10 \%$ (v/v) glycerol and were incubated for $20 \mathrm{~min}$ at $100^{\circ} \mathrm{C}$. For SDS-PAGE, gels with $10 \%(\mathrm{w} / \mathrm{v})$ polyacrylamide were used.

Proteins were transferred onto nitrocellulose membranes and detected using polyclonal antisera against the large subunit of Rubisco, RbcL (Agrisera, Vännäs, Sweden) and PEPC (GeneTex Inc., San Antonio, TX, USA), respectively. Binding of secondary antibodies conjugated with alkaline phosphatase (Sigma-Aldrich, Poznań, Poland) was detected by staining with NBT/BCIP (Knecht and Dimond 1984). 
Analysis of plastid gene transcription

The transcriptional activity of chloroplasts was analyzed by run-on transcription assays performed according to Krupinska (1992). Radiolabeled $\left({ }^{32} \mathrm{P}-\mathrm{UTP}\right)$ transcripts were hybridized with DNA probes specific for plastid genes of $M$. crystallinum that were immobilized on nylon filters (Krupinska 1992). DNA fragments of 600-800 bp were amplified from total DNA. Primers were chosen based on the sequence information of the spinach plastid genome (Acc No AJ 400848, Schmitz-Linneweber et al. 2001).

$p s b A$ forward (GCACTAAATAGGGAGCCGCCG), $p s b A$ reverse (ATGACTGCAATTTTAGAGAGACG $\mathrm{CG})$,

$p s a A$ forward (CAGTATCGGTCAGCCACAGACC), $p s a A$ reverse (GGAACCTACATGCTGATGCTCACG), $r b c L$ forward (GGACGATGCTACCACATCGAGC), $r b c L$ reverse (ACCTACTACGGTACCAGAGTG), $16 \mathrm{~S}$ forward (AGGCGATGATCAGTAGCTGGTCC), $16 \mathrm{~S}$ reverse (ACGAGGGTTGCGCTCGTTGC), $p s b D$ forward (GTATACCCATGGATTGGCC), $p s b D$ reverse (ACTCCAAGAGCACTCATCC), $p s a B$ forward (CTCCATGAGCAAAAGCTCC), $p s a B$ reverse (GGTTTGGTATTGCTACCGC).

Amplified DNA fragments were cloned into pGemT, and plasmid DNA was dotted in a dilution series onto nylon filters as described (Krupinska 1992). After hybridization of filters with radiolabeled run-on transcripts, hybridization intensity of each dot was detected by an imaging plate (Fujifilm Europe, Düsseldorf, Germany) of a Fla5000-BioImager (Fujifilm Europe). The radioactivity measured for spots of equal area was analyzed using the software AIDA Image Analyzer v3.10 (Raytest, Straubenhardt, Germany).

RT-PCR analyses were done as described previously (Niewiadomska and Miszalski 2008). Amplification of 18S-rRNA which was used as a control for equal amounts of cDNA in PCR assays was done with primers supplied by the manufacturer (Quantum RNA universal 18S kit, Ambion Inc., Austin, TX, USA).

\section{Results}

Diurnal changes in the functional state

of the photosynthetic apparatus

Chlorophyll fluorescence measurements revealed a strongly decreased PSII quantum efficiency Y(II) in CAM plants at the end of the night (phase I, Fig. 1a). During the first hour of illumination, a very rapid recovery of PSII quantum yield occurs in CAM plants exceeding the values of $\mathrm{C}_{3}$

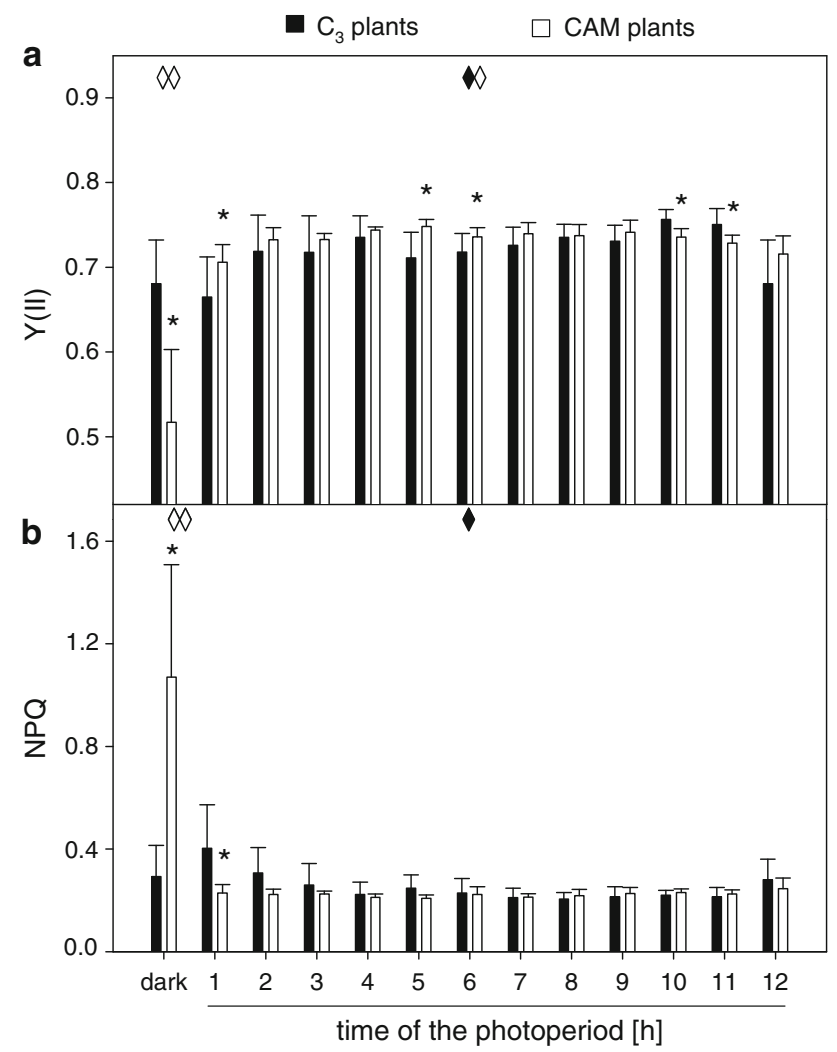

Fig. 1 Diurnal changes in the quantum efficiency of PSII, Y(II) (a) and non-photochemical quenching, NPQ (b) in leaves $M$. crystallinum plants in $\mathrm{C}_{3}$ and CAM state. Values represent mean $\pm \mathrm{SD}(n \geq 9)$. Sign "asterisk" highlights a significant difference between $\mathrm{C}_{3}$ and CAM plants at the same time of the day, as revealed by $t$ test at $P<0.05$. Sign "filled diamond" indicates significant differences in a diurnal pattern of $\mathrm{C}_{3}$ plants at specific time points ( $12 \mathrm{~h}$ of dark, 6 and $12 \mathrm{~h}$ of light) in comparison to the value from first hour of light, as revealed by $t$ test at $P<0.05$. Signs "open diamond" and "open double diamond" indicate significant differences in a diurnal pattern of CAM plants at specific time points $(12 \mathrm{~h}$ of dark, 6 and $12 \mathrm{~h}$ of light) in comparison to the value measured after the first hour of light, as revealed by $t$ test at $P<0.05$ and $P<0.001$, respectively

plants. After $1 \mathrm{~h}$ of illumination, quantum efficiency of PSII was similar in $\mathrm{C}_{3}$ and CAM plants until the middle of photoperiod when a higher value of Y(II) was measured in CAM plants. At the end of photoperiod (10-11 h of light), a decline in PSII quantum efficiency was detected in CAM plants in comparison to $\mathrm{C}_{3}$ plants. At midday, values of $\mathrm{Y}$ (II) were significantly increased in comparison to the values from first hour of illumination, both in $\mathrm{C}_{3}$ plants and in CAM plants. The reduced quantum efficiency $\mathrm{Y}(\mathrm{II})$ in CAM plants at the end of the night in comparison to $\mathrm{C}_{3}$ plants and to CAM plants at the daytime was accompanied by a highly increased NPQ (Fig. 1b). The rapid recovery of $\mathrm{Y}(\mathrm{II})$ in CAM plants during the first hour of the photoperiod was paralleled by a significantly lower NPQ value in comparison to $\mathrm{C}_{3}$ plants. For the remaining of the photoperiod NPQ was similar in $\mathrm{C}_{3}$ and CAM plants (Fig. 1b). 


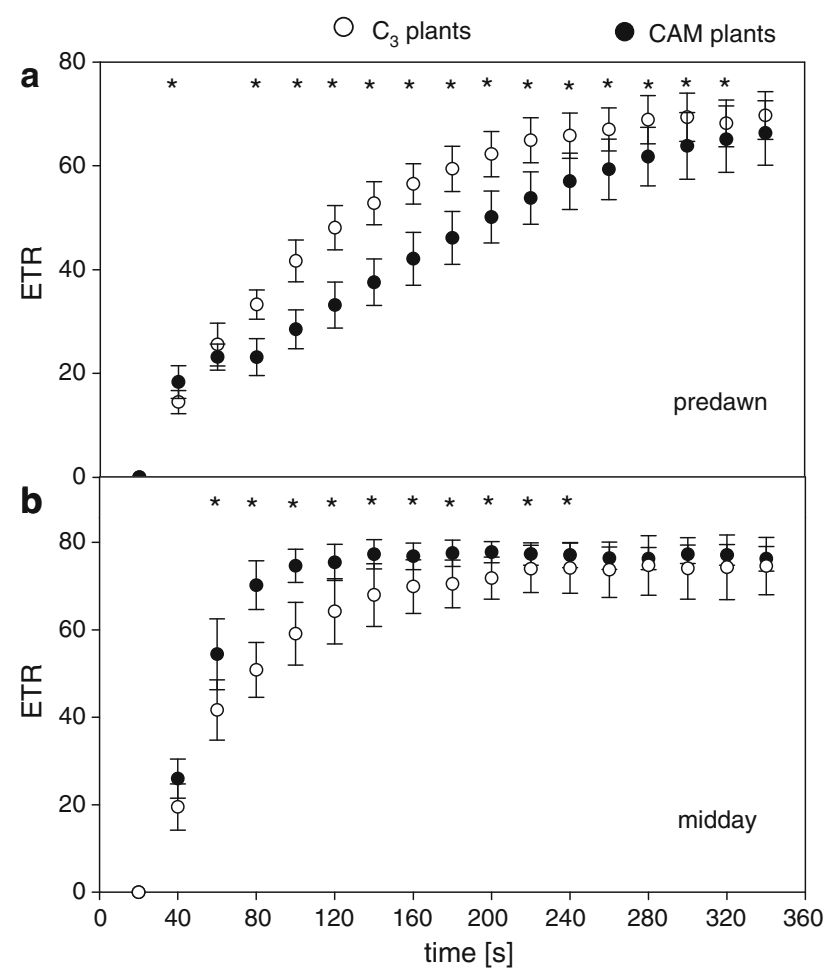

Fig. 2 Induction curves for the rate of electron transport $\left(\mu \mathrm{mol} \mathrm{m} \mathrm{m}^{-2} \mathrm{~s}^{-1}\right)$ in PSII in leaves of $\mathrm{C}_{3}$ and CAM plants of M. crystallinum measured at the end of the night (a) and in the middle of photoperiod (b). In b, the plants were kept in darkness for 15-20 min before the measurements. Values represent mean $\pm \mathrm{SD}(n \geq 9)$. Sign "asterisk" indicates a significant difference between $\mathrm{C}_{3}$ and $\mathrm{CAM}$ plants obtained with the same number of saturating pulses (SP), as revealed by $t$ test at $P<0.05$

Induction of electron transport in PSII was retarded in CAM plants as compared to $\mathrm{C}_{3}$ plants when measured at the end of the night (phase I) (Fig. 2a). At midday, CAM plants, however, showed a more rapid induction of ETR than $\mathrm{C}_{3}$ plants (Fig. 2b) which was accompanied by a faster induction of photochemical quenching (data not shown).

To investigate whether the changes in PSII quantum yield and the differences observed in induction of ETR are accompanied by changes in the functionality of photosystem I, a dual PAM measuring device was used to determine the photosystem I quantum yield $\mathrm{Y}(\mathrm{I})$ at different time points during the day (Fig. 3a). The diurnal changes in Y(I) were observed to be similar to those of Y(II). At the end of the night, a lower $\mathrm{Y}(\mathrm{I})$ in CAM plants was associated with a highly increased value for the donor side limitation $\mathrm{Y}_{\mathrm{ND}}$ (Fig. 3a, b). At the end of the light period, Y(I) similarly as $\mathrm{Y}$ (II) was lowered in CAM plants, in comparison to $\mathrm{C}_{3}$ plants. Although in CAM plants at the beginning of the photoperiod, a decline in $\mathrm{Y}(\mathrm{I})$ was accompanied by a highly increased donor side limitation $\mathrm{Y}_{\mathrm{ND}}$, no such correlation was observed at the end of the light period (Fig. 3a, b). A decreased donor side limitation of $\mathrm{Y}(\mathrm{I})$

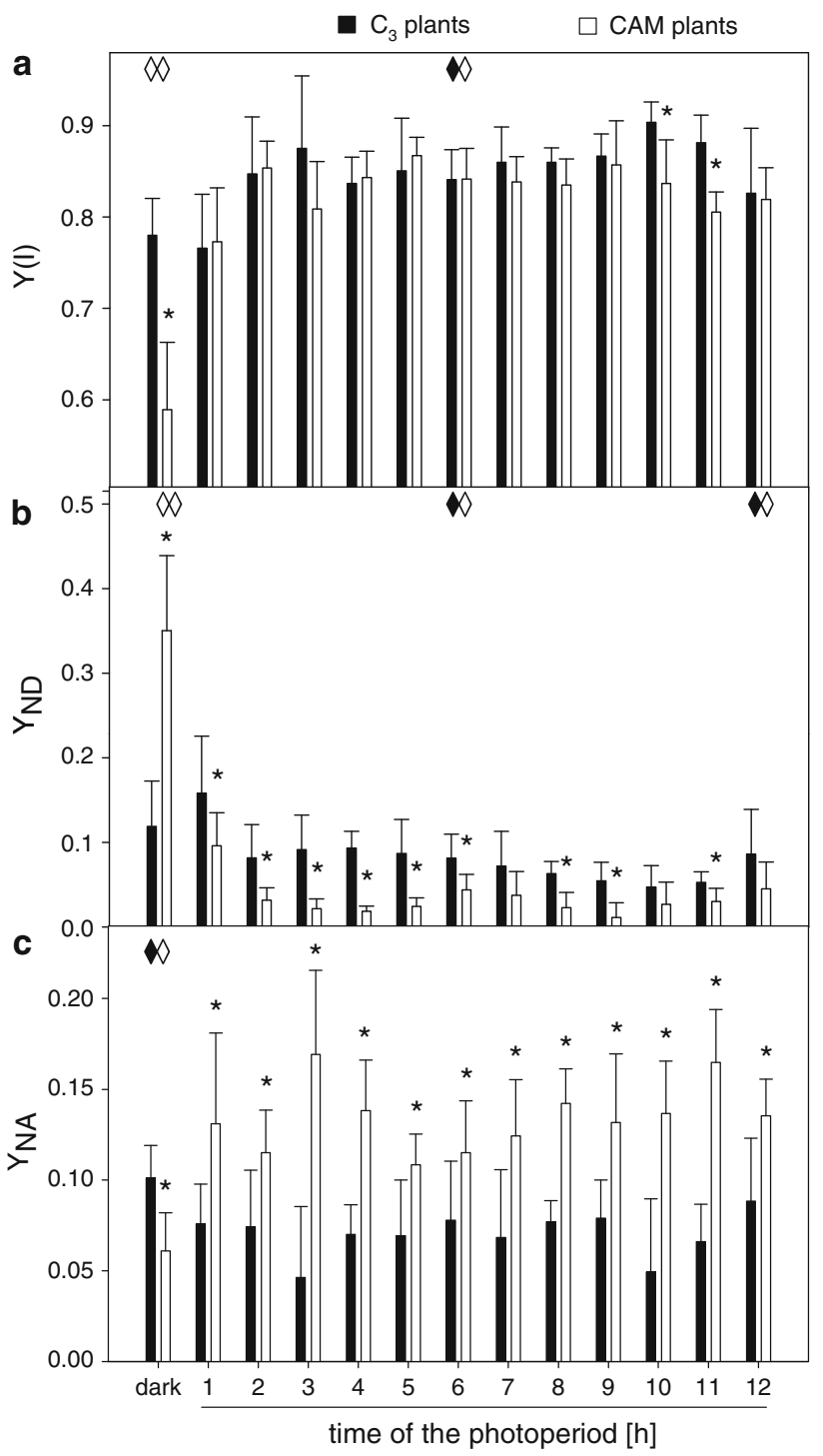

Fig. 3 Diurnal changes in the quantum efficiency of PSI, Y(I) (a), donor side limitation of PSI, $\mathrm{Y}_{\mathrm{ND}}$ (b) and acceptor side limitation, $\mathrm{Y}_{\mathrm{NA}}(\mathbf{c})$ in leaves of $M$. crystallinum plants performing either $\mathrm{C}_{3}$ or CAM metabolism. Values represent mean $\pm \mathrm{SD}(n \geq 9)$. Signs "asterisk" represent significant differences between $\mathrm{C}_{3}$ and CAM plants at the same time of the day, as revealed by $t$ test at $P<0.05$. Sign "filled diamond" indicate significant differences in diurnal patterns of $\mathrm{C}_{3}$ plants at specific time points $(12 \mathrm{~h}$ of dark, 6 and $12 \mathrm{~h}$ of light) in comparison to the value measured after $1 \mathrm{~h}$ of illumination, as revealed by $t$ test at $P<0.05$. Signs "open diamond" and "double diamond" indicate significant differences in diurnal patterns of CAM plants at specific time points ( $12 \mathrm{~h}$ of dark, 6 and $12 \mathrm{~h}$ of light) in comparison to the value measured after $1 \mathrm{~h}$ of illumination, as revealed by $t$ tests at $P<0.05$ and $P<0.001$, respectively

during the photoperiod (in comparison to the beginning of the day) was a common feature of both $\mathrm{C}_{3}$ and CAM plants. During the photoperiod in CAM plants, values of $\mathrm{Y}_{\mathrm{ND}}$ were however significantly lower than in $\mathrm{C}_{3}$ plants. Acceptor side limitation of $\mathrm{Y}(\mathrm{I})$ was significantly decreased in CAM 
plants in comparison to $\mathrm{C}_{3}$ plants at the end of the night (Fig. 3c). In contrast, during the entire photoperiod $\mathrm{Y}_{\mathrm{NA}}$ in CAM plants was highly enhanced.

\section{Ultrastructure of chloroplasts}

In chloroplasts of $\mathrm{C}_{3}$ plants, thylakoids were densely packed between the starch grains and concentrated at the margins of chloroplasts both at predawn and at midday (Fig. 4a). Chloroplasts had clearly distinguishable although irregular grana stacks and also long unstacked thylakoids. While the stroma at predawn had a high electron density in CAM chloroplasts, staining of the stroma at midday was similar to the stroma of $\mathrm{C}_{3}$ chloroplasts. The high density of the stroma during the dark phase could be due to a high osmolarity and high protein content indicative of intensive metabolic processes. At predawn the rather long thylakoids of CAM chloroplasts appeared to be stacked, while at midday, they appeared to be unstacked and extremely swollen (Fig. 4a, b). In chloroplasts from CAM plants, the average thylakoid width was estimated to be $0.095 \pm$ $0.022 \mu \mathrm{m}$ (mean $\pm \mathrm{SD} ; n=26)$. This value was significantly ( $t$ test; $P<0.001$ ) higher in comparison to the average thylakoid width in chloroplasts from $\mathrm{C}_{3}$ plants: $0.071 \pm 0.013 \mu \mathrm{m}$, respectively. The swelling of the lumen at midday in CAM plants might be indicative of an altered osmotic pressure/ionic composition.

Immunological analyses of proteins of the photosynthetic apparatus

To explore whether the diurnal differences observed in functionality of the photosystems of CAM and $\mathrm{C}_{3}$ plants were accompanied by changes in the composition of the a

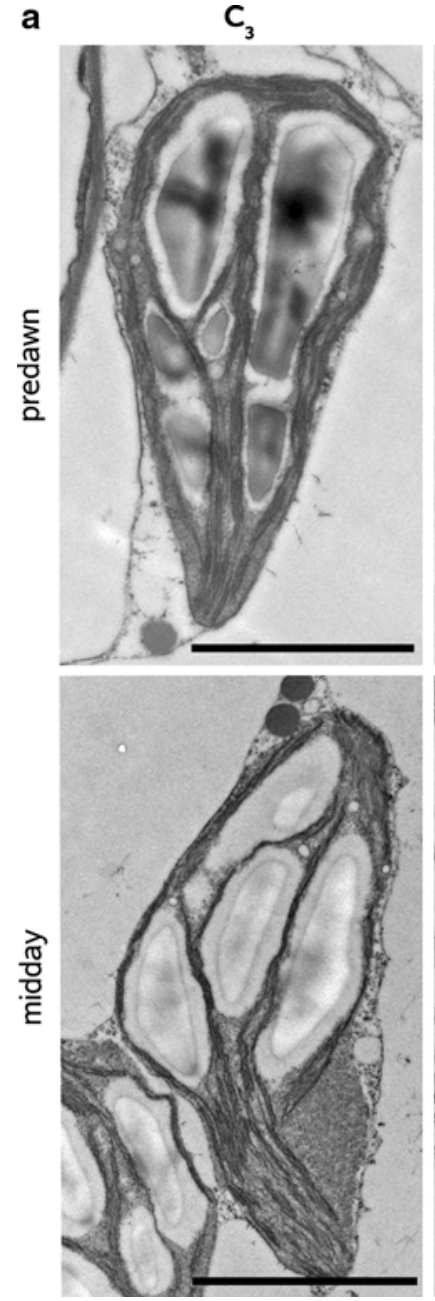

CAM

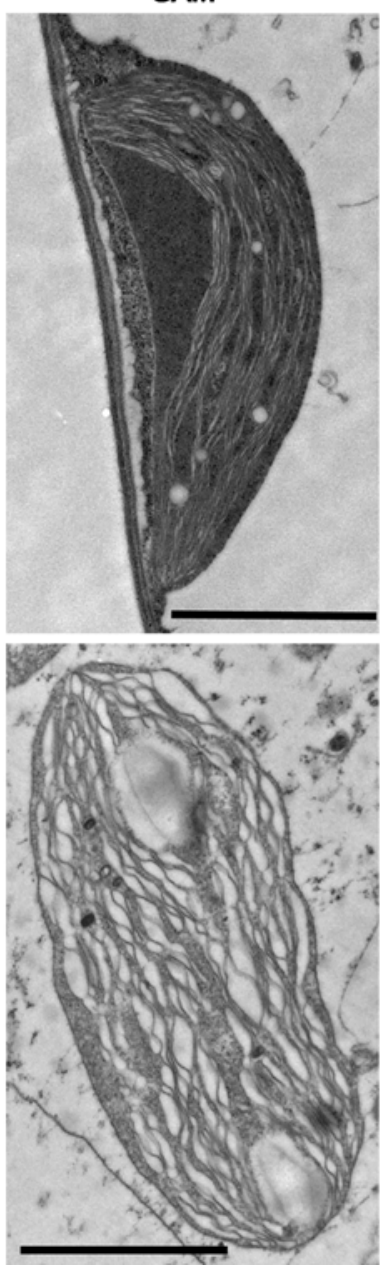

b

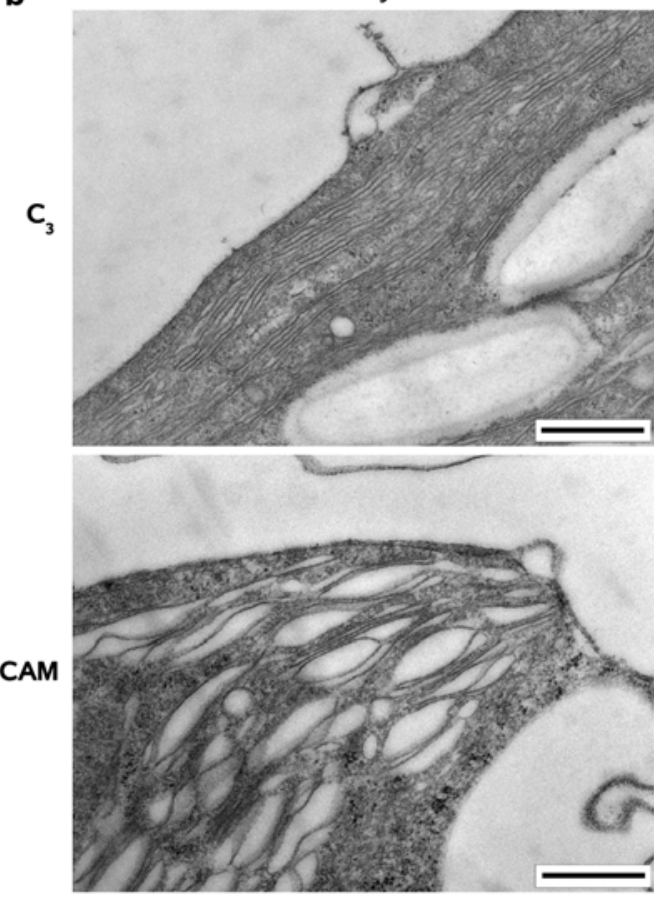

Fig. 4 Electron micrographs of chloroplasts of M. crystallinum plants performing either $\mathrm{C}_{3}$ or CAM metabolism. Samples for analysis of chloroplast ultrastructure were taken at the end of the night (predawn) and at midday, respectively. The bar in the overview pictures (a) represents a distance of $2 \mu \mathrm{m}$. In panel $\mathbf{b}$, the thylakoid membrane system at midday is shown at higher magnification. The bar on panels (b) represents a distance of $0.5 \mu \mathrm{m}$. The photos are typical examples of at least 26 repetitions 
Fig. 5 Immunological detection of the large subunit of Rubisco (RbcL) and PEPC polypeptide. Protein samples were prepared from $\mathrm{C}_{3}$ and CAM $M$. crystallinum leaves collected at different times of the day. Gels were loaded with $7 \mu \mathrm{g}$ of protein

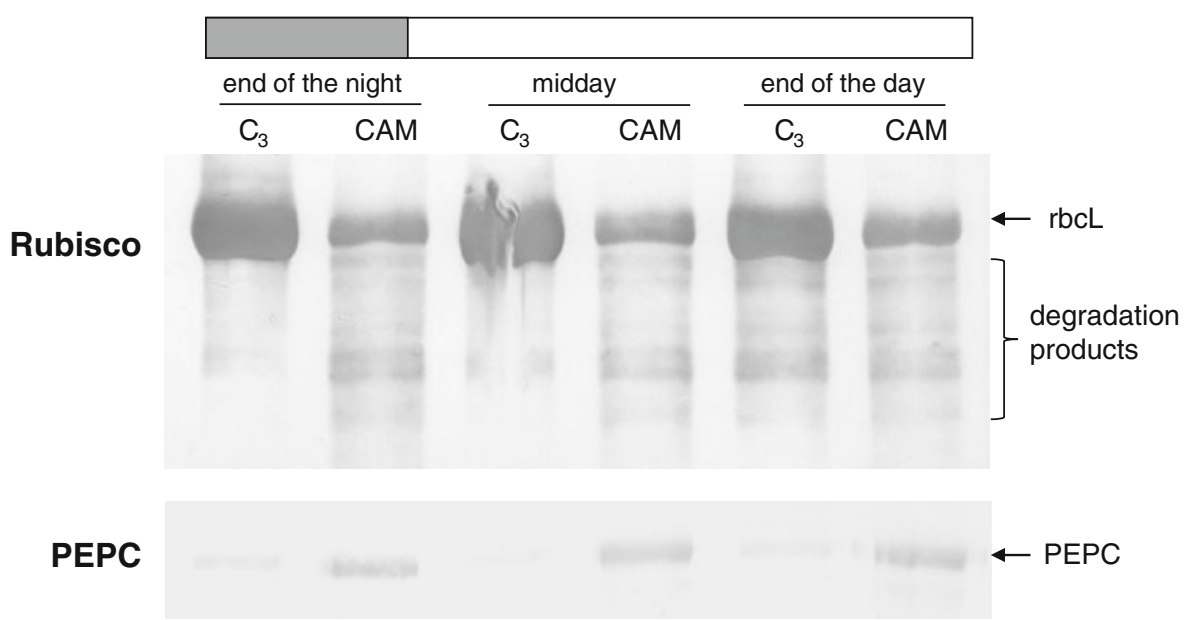

photosynthetic apparatus, the amount of Rubisco was immunologically analyzed. Levels of Rubisco large subunit were compared in leaves collected at the end of the night, at midday and at the end of the light period, respectively (Fig. 5). Strikingly, the amount of Rubisco in CAM plants was strongly reduced in comparison to $\mathrm{C}_{3}$ plants (Fig. 5). Rubisco degradation products of lower molecular mass in the range of $44-53 \mathrm{kDa}$ were also visualized on the blots. In contrast to Rubisco, the amount of PEPC was highly enhanced in CAM plants (Fig. 5).

Expression of genes encoding photosystem II and I reaction centers and Rubisco subunits

To investigate whether the observed diurnal changes in protein levels are regulated by changes in gene expression, semi-quantitative RT-PCR was used to determine transcript levels of plastid genes $p s b A, p s a A / B, r b c L$ and of the nuclear gene $r b c S$ (Fig. 6a). As constitutive controls, cytoplasmic 18SrRNA and plastid 16SrRNA, respectively, were amplified. CAM plants at midday had a higher level of $p s b A$ mRNA in comparison to $\mathrm{C}_{3}$ plants. This might reflect a high demand for new synthesis of the D1 protein.

In addition, the levels of $p s a A$ and $r b c L$ transcripts were observed to be enhanced in CAM plants at midday as compared to $\mathrm{C}_{3}$ plants. The level of nuclear $r b c S$ mRNA underwent corresponding diurnal changes (Fig. 6a). This suggests that at midday besides the D1 protein also the reaction center of photosystem I and Rubisco have a higher turnover in CAM plants as compared to $\mathrm{C}_{3}$ plants.

If CAM plants during the day have a higher demand for resynthesis of PSII reaction center proteins and Rubisco subunits, enhanced transcriptional activities of the corresponding genes might be expected. To analyze plastid gene transcription at the end of the night and at midday, run-on transcription assays with isolated plastids were performed. Radiolabeled run-on transcripts were hybridized to gene-specific DNA fragments immobilized on nylon membranes. The DNA probes were specific for $p s b A$, $p s b D, p s a A / B, r b c L$ and the $r r n$ operon genes of $M$. crystallinum (Fig. 6b). Based on the transcription of the $r r n$ operon, at the end of the night, the relative transcription rates of all genes analyzed was similar in CAM and $\mathrm{C}_{3}$ plants. Transcription rates of $p s b A$ and $r b c L$ genes were, however, slightly lower in CAM plants. While in $\mathrm{C}_{3}$ plants, the relative transcription rates of the selected genes did barely change during illumination, CAM plants at midday had much higher rates of transcription than CAM plants at the end of the night (Fig. 6b). The increase in transcription was even more pronounced in case of the $p s a A / B$ operon than in case of the $p s b A$ gene (Fig. 6b).

The most obvious increase in the transcription rate during the first half of the light period of CAM plants was observed for the $r b c L$ gene (Fig. 6b) which at the end of the night was lower in CAM plants as compared to $\mathrm{C}_{3}$ plants. The increase in relative transcription of the $r b c L$ gene in CAM plants is evident not only when based on the transcription of the $r r n$ operon, but also when based on the transcription of the $p s b A$ gene (Fig. 6b) suggesting a specifically enhanced transcription rate of the $r b c L$ gene of CAM plants during the light period.

\section{Discussion}

Diurnal changes in photosynthesis of CAM plants

Analyses of functional parameters of the photosynthetic apparatus in $\mathrm{C}_{3}$ and CAM plants at different time points of the day revealed that in CAM plants, PSI and PSII quantum yields undergo considerable diurnal fluctuations of the same kind. Two effects could be distinguished. First, yields of both photosystems were strongly decreased in CAM plants at the beginning of the day, but reached similar or 


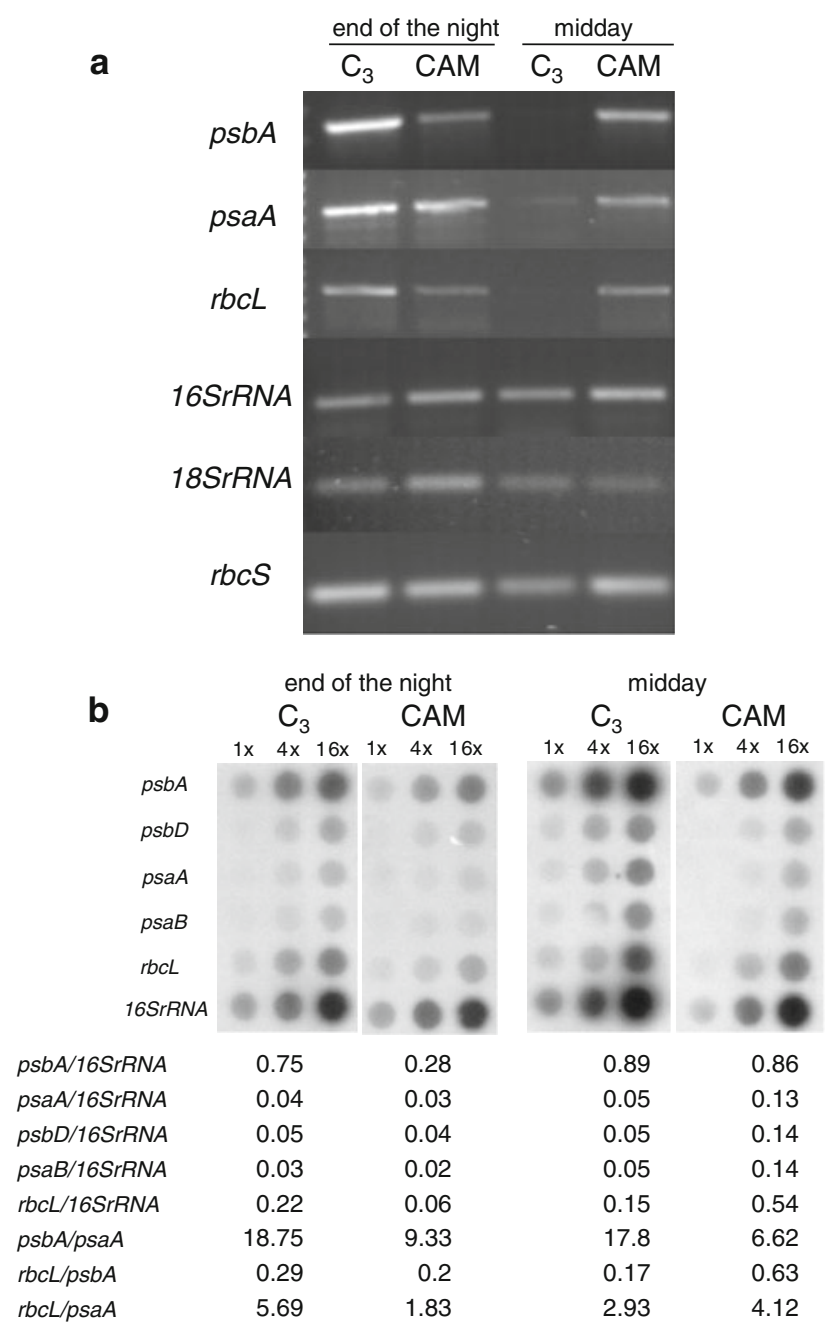

Fig. 6 Analyses of gene expression. a Abundance of $p s b A$, psaA, $r b c L, 18 \mathrm{~S}$ and $r b c S$ transcripts in leaves of $\mathrm{C}_{3}$ plants and in CAMinduced plants as revealed by semi-quantitative RT-PCR. For these analyses, RNA was extracted from leaves collected at the end of the night, at midday and at the end of the day. b Ratios of relative transcriptional activities of selected genes obtained by run-on analysis. Plastids were isolated from leaves of $M$. crystallinum plants in $\mathrm{C}_{3}$ and $\mathrm{CAM}$ state at the end of the night and at midday. M. crystallinum ptDNA-dot-blot filters representing different genes were hybridized with ${ }^{32} \mathrm{P}$-labeled run-on transcripts derived from $\mathrm{C}_{3}$ and CAM plants, respectively. These results are representative of at least three repetitions

higher levels as in $\mathrm{C}_{3}$ plants already during the first hour of illumination. Secondly, the yields of both photosystems decreased again in CAM plants at the end of the light period suggesting that the mechanism maintaining the enhanced yields at midday was exhausted. The mechanisms underlying the decline in photosystems' efficiencies differ between the two transition phases (night/day and day/night) as indicated by the redox state of P700. At the onset of the day, limitation of PET is associated with a highly oxidized state of P700 (donor side limitation of PSI) and slower induction of ETR in PSII paralleled by a highly increased NPQ. This is in agreement with the earlier results reported for CAM plants (Maxwell et al. 1999a; Keiller et al. 1994; Schöttler et al. 2002; Griffiths et al. 2008) and may suggest a limited electron flux from PSII via the cytochrome $b_{6} f$ complex and plastocyanin. Interestingly, this result is different from the numerous data obtained with $\mathrm{C}_{3}$ plants, in which a limitation of PET during darklight transition is attributed to low level of PSI acceptors (Klughammer and Schreiber 1994 and refs therein). In contrast, evening restriction of PET in CAM plants is most likely limited by electron acceptors from PSI (acceptor side limitation of PSI, i.e. highly reduced P700).

Several reasons may account for the low efficiencies of PSII and PSI in CAM plants at the onset of the day. A high ATP level at the end of the night has been shown in several CAM species (Niewiadomska et al. 2004; Chen and Nose 2004). This might restrict the efficiency of the photosystems and the rate of PET during induction of photosynthesis (Gilmore and Yamamoto 1992). Furthermore, an elevated level of carboxylic acids accumulating during the night might cause acidification within the chloroplasts (Neuhaus and Schulte 1996). Acidification in turn can lead to a decreased level of available bicarbonate, thus downregulating both PSII and PSI activities (Klughammer and Schreiber 1994; van Rensen 2002; Stemler 2002). Another reason for a low level of $\mathrm{CO}_{2}$, which in CAM plants might lead to a downregulation of PSII at the end of the night and might be high activity of PEPC keeping the stomata open during the night. A close correlation between the extent of CAM and ETR rate at the onset of the day has been recently documented by Griffiths et al. (2008). A slower morning activation of Rubisco was also shown in CAM plants in conjunction with low carbamylation state (Maxwell et al. 1999a). This could result either from a low level of $\mathrm{CO}_{2}$ or a low amount of Rubisco activase, and is likely to evoke an inhibitory effect on PET (Griffiths et al. 2002, 2008). Moreover, a highly increased level of reduced plastoquinone at the end of the night has been reported for CAM plants (Winter and Demmig 1987; Krieger et al. 1998). Taken together, it seems that a strong limitation of PET at the onset of the day is a common feature of CAMperforming plants.

Further on during the day, a rapid recovery of PET takes place in CAM plants. This is evident by increased Y(I) and Y(II) during first hour of illumination. A faster induction of ETR in PSII at midday points to a higher capacity of electron sinks, which may have resulted from an increased activity of Rubisco, as a consequence of increased concentration of $\mathrm{CO}_{2}$. However, a persistent situation of reduced acceptors of PSI $\left(\mathrm{Y}_{\mathrm{ND}}\right)$ in CAM plants during daytime seems to be largely independent of a CAM-related fluctuations in $\mathrm{CO}_{2}$ level. This may point to the limitation imposed by the low availability of Rubisco, which most 
likely is caused by its degradation. Experiments of Keiller et al. (1994) documented state transition during most of the daytime in M. crystallinum CAM plants. One may suppose that migration of originally PSII-associated light harvesting complexes to PSI during state transition could contribute to the acceptor side limitation of PSI.

\section{Chloroplast ultrastructure}

To examine whether the diurnal differences in function of the photosynthetic apparatus of CAM plants are accompanied by structural changes of the thylakoid membrane system ultrastructural analyses were performed. When compared with $\mathrm{C}_{3}$ plants and to CAM plants at the end of the night, CAM plants at midday showed a severe thylakoid swelling as already reported by Paramonova et al. (2004). The structure of the thylakoid membrane system in CAM chloroplasts at midday resembles the structure of bundle sheath chloroplasts in $\mathrm{C}_{4}$ plants of the NADP-ME type which also have long unstacked thylakoids (Woo et al. 1970; Edwards et al. 2004; Darie et al. 2006) and lose photosystem II during their development (Westhoff et al. 1990; Oswald et al. 2005). As shown by Yamane et al. (2003a, b), thylakoid swelling might be also indicative of damage caused by salt. The concentration of salt is, however, unlikely to change during the day and therefore cannot determine the diurnal fluctuations observed in chloroplast structure of CAM plants of M. crystallinum.

It is tempting to speculate that thylakoid swelling at daytime might play a role in adaptation of the photosynthetic apparatus to the CAM type of photosynthesis. This idea is in accordance with the earlier findings obtained on the $\mathrm{CAM} / \mathrm{C}_{3}$ intermediate plant $G$. monostachia, where induction of CAM by high irradiance was accompanied by a decreased content of thylakoids, lower extent of thylakoid stacking and a reduced level of Rubisco (Maxwell et al. 1999b). In de-stacked thylakoid membranes as observed at midday in CAM plants, the contribution of PSII to PET, and hence, to $\mathrm{CO}_{2}$ fixation at midday is limited (Kirchhoff et al. 2000). Thylakoid membrane architecture of CAM plants at midday resembled that of chloroplasts trapped in a state II with the high activity of cyclic electron transport (Chuartzman et al. 2008). This suggests that CAM chloroplasts temporally have a functional state similar to the spatially specialized bundle sheath chloroplasts of $\mathrm{C}_{4}$ plants.

Diurnal changes in the composition

of the photosynthetic apparatus

The reduction in the level of Rubisco (RbcL) during stressinduced $\mathrm{C}_{3}-\mathrm{CAM}$ shift might be caused by proteolysis. Neuhaus and Schulte (1996) demonstrated that the $\mathrm{C}_{3}-$ CAM shift in $M$. crystallinum is accompanied by an intensive remobilization of starch providing substrates for nocturnal carboxylation by PEPC or for respiration. We suppose that intensive nocturnal degradation of Rubisco might contribute to the supply of substrates for nocturnal fixation of $\mathrm{CO}_{2}$. It is noteworthy that the reduced level of Rubisco in CAM plants limits the capacity of the protective photorespiratory pathway and cause a decrease in PET and in quantum efficiency of both photosystems in phases when accumulated $\mathrm{CO}_{2}$ resources are not available. This interpretation is in agreement with the earlier findings showing a decreased activity of catalase after a $\mathrm{C}_{3}-\mathrm{CAM}$ shift (Niewiadomska et al. 1999; Niewiadomska and Miszalski 2008). A dramatic decrease in the level of Rubisco may exert a limiting effect on PET, as visualized by acceptor side limitation of PSI.

Expression of photosynthesis associated genes in response to the $\mathrm{C}_{3}-\mathrm{CAM}$ shift

RT-PCR showed that CAM plants at midday have enhanced levels of transcripts for thylakoid membrane proteins and Rubisco subunits when compared with $\mathrm{C}_{3}$ plants. This might reflect a high demand for new synthesis of these proteins. A repression of protein synthesis by high salinity, as demonstrated by Hertwig et al. (1992) could be the reason for the enhanced expression of the corresponding genes in the light. Except $r b c S$, all genes tested are located in plastids. The high levels of plastid mRNAs observed in CAM plants at midday were observed to be accompanied by higher transcription rates of genes encoding $p s b A, p s b D$, $p s a A, p s a B$ and $r b c L$. The most obvious increase in the relative transcription rate of CAM plants during the morning illumination was observed for the $r b c L$ gene. This increase could be indicative of a CAM-specific effect on Rubisco regulation involving a shortage of electron acceptors of PSI, as indicated by $\mathrm{Y}_{\mathrm{NA}}$ data. However, so far, it has been suggested that PET may affect the expression of $r b c L$ gene predominantly at the level of transcript stability and translation (Pfannschmidt 2003). It is also tempting to speculate that transcription of the $r b c L$ gene might be regulated by the internal $\mathrm{CO}_{2}$ level (low $\mathrm{CO}_{2}$ at night and increased $\mathrm{CO}_{2}$ during illumination until midday). The only indication of $\mathrm{CO}_{2}$-responsive elements on the promoter region of rbcLS genes was reported for Synechococcus sp. PCC7002 (Onizuka et al. 2003). Thus, it remains to be investigated whether $\mathrm{CO}_{2}$ or $\mathrm{P} 700$ redox state may regulate Rubisco at the level of transcription in higher plants.

\section{Conclusion}

After the salinity-induced $\mathrm{C}_{3}-\mathrm{CAM}$ shift in $M$. crystallinum a strong limitation of PSII and PSI efficiencies occurs 
at the onset of the day. A recovery of the efficiencies of both photosystems during the day in CAM plants might be attributed to the increasing concentration of $\mathrm{CO}_{2}$ in the proximity of Rubisco active sites. Swelling and de-stacking of thylakoid membranes in CAM chloroplasts suggests a decreased contribution of PSII (linear flux) to photosynthesis. It is also shown that metabolic change induced by stress is accompanied by a drastic decrease in the amount of Rubisco which may limit the capacity of electron acceptors of PSI. To provide transcripts required for new synthesis of proteins undergoing proteolysis in CAM plants at midday, transcription of plastid genes encoding components of the photosynthetic apparatus and the large subunit of Rubisco is specifically increased. Furthermore, stimulation of $r b c L$ gene transcription might be a specific response to the elevated $\mathrm{CO}_{2}$ level in CAM plants during the early light phase.

Acknowledgments The DAAD is thanked for supporting the collaboration between the group of Z. Miszalski, Krakow, and the group of K. Krupinska, Kiel. We also thank the German Research Foundation for support of E. Niewiadomska during a 3 months stay at the University of Kiel (DFG, Kr1350/11-1). Furthermore, we acknowledge the Polish Research Grant 633/N-COST/09/2010/0. We acknowledge also the expert technical assistance of Anke Schäfer and Marita Beese, University of Kiel. We thank the Center of Biochemistry and Molecular Biology (ZBM, CAU Kiel) for providing bioimaging facilities for this research.

Open Access This article is distributed under the terms of the Creative Commons Attribution Noncommercial License which permits any noncommercial use, distribution, and reproduction in any medium, provided the original author(s) and source are credited.

\section{References}

Adams P, Nelson DE, Yamada S, Chmara W, Jensen RG, Bohnert HJ, Griffiths H (1998) Growth and development of Mesembryanthemum crystallinum (Aizoaceae). New Phytol 138:171-190

Bohnert HJ, Cushman JC (2000) The ice plant cometh: lessons in abiotic stress tolerance. J Plant Growth Regul 19:334-346

Borland AM, Taybi T (2004) Synchronization of metabolic processes in plants with crassulacean acid metabolism. J Exp Bot 55:1255-1265

Chen L-S, Nose A (2004) Day-night changes of energy-rich compounds in crassulacean acid metabolism (CAM) species utilizing hexose and starch. Ann Bot 94:449-455

Chuartzman SG, Nevo R, Shimoni E, Charuvi D, Kiss V, Ohad I, Brumfeld V, Reich Z (2008) Thylakoid membrane remodeling during state transition in Arabidopsis. Plant Cell 20:1029-1039

Cushman JC, Bohnert H (1999) Crassulacean acid metabolism: molecular genetics. Annu Rev Plant Physiol Plant Mol Biol 50:305-332

Darie CC, De Pascalis L, Mutschler B, Haehnel W (2006) Studies of the Ndh complex and photosystem II from mesophyll and bundle sheath chloroplasts of the $\mathrm{C}_{4}$-type plant Zea mays. J Plant Physiol 163:800-808

Edwards GE, Franceschi VR, Vosniesenskaya EV (2004) Single-cell $\mathrm{C}_{4}$ photosynthesis versus the dual-cell (Kranz) paradigm. Annu Rev Plant Bil 55:173-196
Genty B, Briantais J-M, Baker NR (1989) The relationship between the quantum yield of photosynthetic electron transport and quenching of chlorophyll fluorescence. Biochim Biophys Acta 990:87-92

Gilmore AM, Yamamoto HY (1992) Dark induction of zeaxanthindependent nonphotochemical fluorescence quenching mediated by ATP. Proc Natl Acad Sci USA 89:1899-1903

Griffiths H, Helliker B, Roberts A, Haslam RP, Girnus J, Robe WE, Borland AM, Maxwell K (2002) Regulation of Rubisco activity in crassulacean acid metabolism plants: better late than never. Funct Plant Biol 29:689-696

Griffiths H, Robe WE, Girnus J, Maxwell K (2008) Leaf succulence determines the interplay between carboxylase systems and light use during crassulacean acid metabolism in Kalanchoe species. J Exp Bot 59:1851-1861

Gruissem W, Greenberg BM, Zurawski G, Hallick RB (1986) Chloroplast gene expression and promoter identification in chloroplast extracts. Methods Enzymol 118:253-270

Hertwig B, Streb P, Feierabend J (1992) Light dependence of catalase synthesis and degradation in leaves and the influence of interfering stress conditions. Plant Physiol 100:1547-1553

Keiller DR, Slocombe SP, Cockburn W (1994) Analysis of chlorophyll $a$ fluorescence in $\mathrm{C}_{3}$ and CAM forms of Mesembryanthemum crystallinum. J Exp Bot 45:325-334

Kirchhoff H, Horstmann S, Weis E (2000) Control of the photosynthetic electron transport by $\mathrm{PQ}$ diffusion microdomains in thylakoids of higher plants. Biochim Biophys Acta 1459: $148-168$

Klughammer C, Schreiber U (1994) An improved method, using saturating light pulses, for the determination of photosystem I quantum yield via $\mathrm{P} 700^{+}$-absorbance changes at $830 \mathrm{~nm}$. Planta 192:261-268

Knecht DA, Dimond RL (1984) Visualization of antigenic proteins on blots. Anal Biochem 136:180-184

Köster S, Winter K (1985) Light scattering as an indicator of the energy state in leaves of the crassulacean acid metabolism plant Kalanchoë pinnata. Plant Physiol 79:520-524

Kramer DM, Johnson G, Kiirats O, Edwards GE (2004) New flux parameters for the determination of QA redox state and excitation fluxes. Photosynth Res 79:209-218

Krieger A, Bolte S, Dietz K-J, Ducruet J-M (1998) Thermoluminescence studies on the facultative crassulacean acid metabolism plant Mesembryanthemum crystallinum L. Planta 205:587-594

Krupinska K (1992) Transcriptional control of plastid gene expression during development of primary foliage leaves of barley grown under a daily light-dark regime. Planta 186:294-303

Laemmli UK (1970) Cleavage of structural proteins during the assembly of the head of bacteriophage T4. Nature 227:680-685

Lüttge U (2004) Ecophysiology of crassulacean acid metabolism (CAM). Ann Bot 93:629-652

Maxwell K, Borland AM, Haslam RP, Helliker BR, Roberts A, Griffiths H (1999a) Modulation of Rubisco activity during the diurnal phases of the crassulacean acid metabolism plant Kalanchoe daigremontiana. Plant Physiol 121:849-856

Maxwell K, Marrison JL, Leech RM, Griffiths H, Horton P (1999b) Chloroplast acclimation in leaves of Guzmania monostachia in response to high light. Plant Physiol 121:89-95

Neuhaus HE, Schulte N (1996) Starch degradation in chloroplasts isolated from $\mathrm{C}_{3}$ or CAM (crassulacean acid metabolism)induced Mesembryanthemum crystallinum L. Biochem J 318:945-953

Niewiadomska E, Borland AM (2008) Crassulacean acid metabolism: a cause or consequence of oxidative stress in planta? In: Lüttge UE, Beyschlag W, Murata J (eds) Progress in botany, vol 69. Springer, Berlin, pp 247-266 
Niewiadomska E, Miszalski Z (2008) Partial characterization and expression of leaf catalase in the CAM-inducible halophyte Mesembryanthemum crystallinum L. Plant Physiol Biochem 46:421-427

Niewiadomska E, Miszalski Z, Ślesak I, Ratajczak R (1999) Catalase activity during $\mathrm{C}_{3}-\mathrm{CAM}$ transition in Mesembryanthemum crystallinum L. leaves. Free Radic Res 31:S251-S256

Niewiadomska E, Karpinska B, Romanowska E, Ślesak I, Karpinski S (2004) A salinity-induced $\mathrm{C}_{3}-\mathrm{CAM}$ transition increases energy conservation in the halophyte Mesembryanthemum crystallinum L. Plant Cell Physiol 45:789-794

Nobel PS (1991) Achievable productivities of certain CAM plants: basis for high values compared with $\mathrm{C} 3$ and $\mathrm{C} 4$ plants. New Phytol 119:183-205

Noctor G, Foyer CH (1998) A reevaluation of the ATP:NADPH budget during $\mathrm{C} 3$ photosynthesis: a contribution from nitrate assimilation and its associated respiratory activity. J Exp Bot 49:1895-1908

Onizuka T, Akiyama H, Endo S, Kanai S, Hirano M, Tanaka S, Miyasaka $\mathrm{H}$ (2003) $\mathrm{CO}_{2}$ response for expression of ribulose-1, 5-bisphosphate carboxylase/oxygenase genes is inhibited by AT-rich decoy in the cyanobacterium. FEBS Lett 542:42-46

Osmond CB (1978) Crassulacean acid metabolism: a curiosity in context. Annu Rev Plant Physiol 29:379-414

Oswald A, Streubel M, Ljungberg U, Hermans J, Eskins K, Westhoff $P$ (2005) Differential biogenesis of photosystem-II in mesophyll and bundle-sheath cells of 'malic' enzyme $\mathrm{NADP}^{+}$-type $\mathrm{C}_{4}$ plants. A comparative protein and RNA analysis. Eur J Biochem 190:185-194

Paramonova NV, Shevyakova NI, Kuznietzov VV (2004) Ultrastructure of chloroplasts and their storage inclusions in the primary leaves of Mesembryanthemum crystallinum affected by putrescine and $\mathrm{NaCl}$. Russian J Plant Physiol 51:86-96

Pfannschmidt T (2003) Chloroplast redox signals: how photosynthesis control its own genes. Trends Plants Sci 8:33-41

Reynolds ES (1963) The use of lead citrate at high $\mathrm{pH}$ as an electronopaque stain in electron microscopy. J Cell Biol 17:208-212

Schmitz-Linneweber C, Maier RM, Alcaraz J-P, Cottet A, Herrmann RG, Mache R (2001) The plastid chromosome of spinach (Spinacia oleracea): complete nucleotide sequence and gene organization. Plant Mol Biol 45:307-315
Schöttler MA, Kirchhoff H, Siebke K, Weis E (2002) Metabolic control of photosynthetic electron transport in crassulacean acid metabolism-induced Mesembryanthemum crystallinum. Funct Plant Biol 29:697-705

Ślesak I, Miszalski Z, Karpinska B, Niewiadomska E, Ratajczak R, Karpinski S (2002) Redox control of oxidative stress responses in the $\mathrm{C}_{3}$-CAM intermediate plant Mesembryanthemum crystallinum. Plant Physiol Biochem 40:669-677

Stemler AJ (2002) The bicarbonate effect, oxygen evolution, and the shadow of Otto Warburg. Photosynth Res 73:177-183

Van Rensen JJS (2002) Role of bicarbonate at the acceptor side of photosystem II. Photosynth Res 73:185-192

Westhoff P, Schrubar H, Oswald A, Streubel M, Offermann K (1990) Biogenesis of photosystem II in C3 and C4 plants-a model system to study developmentally regulated and cell-specific expression of plastids genes. In: Baltscheffsky M (ed) Curr Res Photosynth, vol III. Kluwer Academic Press, The Netherlands, pp 483-490

Winter K, Demmig B (1987) Reduction state of Q and nonradiative energy dissipation during photosynthesis in leaves of a crassulacean acid metabolism plant, Kalanchoë daigremontiana Hamet et Perr. Plant Physiol 85:1000-1007

Winter K, Holtum JAM (2007) Environment or development? Lifetime net $\mathrm{CO}_{2}$ exchange and control of the expression of crassulacean acid metabolism in Mesembryanthemum crystallinum. Plant Physiol 14:98-107

Winter K, Smith JAC (1996) Crassulacean acid metabolism: current status and perspectives. In: Winter K, Smith JAC (eds) Crassulacean acid metabolism. Biochemistry, ecophysiology and evolution. Springer, Berlin, pp 389-426

Woo KC, Anderson JM, Boardman NK, Downton WJS, Osmond CB, Thorne SW (1970) Deficient photosystem II in agranal bundle sheath chloroplasts of $\mathrm{C}_{3}$ plants. Proc Natl Acad Sci USA 67:18-25

Yamane K, Hayakawa K, Kawasaki M, Taniguchi M, Miyake H (2003a) Bundle sheath chloroplasts of rice are more sensitive to drought stress than mesophyll chloroplasts. J Plant Physiol 160:1319-1327

Yamane K, Kawasaki M, Taniguchi M, Miyake H (2003b) Differential effects of $\mathrm{NaCl}$ and polyethylene glycol on the ultrastructure of chloroplasts in rice seedlings. J Plant Physiol 160:573-575 